General paper

\title{
Neutron Diffraction Study of Thermal Residual Stress in Ceramic Composite
}

\author{
Yoshiaki AKInIwA*, Keisuke TANAKA*, Nobuaki MinaKawA** and Yukio MoRII** \\ *Department of Mechanical Engineering, Nagoya University, \\ Furo-cho, Chikusa-ku, Nagoya 464-8603, Japan \\ ** Japan Atomic Energy Research Institute, Tokai, Nakagun 319-1195, Japan
}

\begin{abstract}
The residual stress in ceramic composites of alumina mixed with various volume fractions of zirconia, $\mathrm{Al}_{2} \mathrm{O}_{3} / \mathrm{ZrO}_{2}$, and of silicon carbide, $\mathrm{Al}_{2} \mathrm{O}_{3} / \mathrm{SiC}$, was measured by the neutron diffraction method. The thermal residual stress of each constituent phase was measured as a function of the second phase. The phase stresses were determined from the neutron diffractions of $\mathrm{ZrO}_{2} 202, \mathrm{Al}_{2} \mathrm{O}_{3} 113, \mathrm{Al}_{2} \mathrm{O}_{3} 116$, SiC 220 and $\mathrm{SiC} 311$. In $\mathrm{Al}_{2} \mathrm{O}_{3} / \mathrm{ZrO}_{2}$ composites, the residual stress in the alumina phase was compression and that in the zirconia phase was tension. On the other hand, in $\mathrm{Al}_{2} \mathrm{O}_{3} / \mathrm{SiC}$ composites, the residual stress in the alumina phase was tension, and increased linearly with the silicon carbide volume fraction. The residual stresses were introduced by the mismatch of the coefficient of thermal expansion. The change of the residual stress with volume fraction of the second phase agreed well with the theoretical prediction based on Eshelby's inclusion model.
\end{abstract}

Key words: Residual stress, Neutron stress measurement, X-ray stress measurement, Ceramic composite, Phase stress, Inclusion model

\section{INTRODUCTION}

Ceramic composites have some advantages such as high fracture toughness and strength $[1,2]$. Since the coefficient of thermal expansion of the second phase is different from that of matrix, the residual stress is induced during cool-down from the fabrication temperature. The residual stress has a significant effect on the mechanical properties and strength of the composites. The residual stress is different between the matrix and the second phase, so it is important to evaluate the stress state of each phase. The X-ray and neutron diffraction methods can detect separately the stress in each constituent phase of the composite. Tanaka et al. [1-4] successfully evaluated the effect of volume fraction of constituent phase on the phase stress by the X-ray diffraction method. However, X-rays measure only near-surface stress. On the other hand, neutrons are high penetrating probes, allowing the investigation of the interior of materials. Akiniwa et al. [5, 6] evaluated the phase stress in an aluminum alloy reinforced with silicon carbide particules under uniaxial loading by the neutron diffraction method.

In the present paper, the neutron diffraction method was used to measure the phase stresses in two kinds of ceramic composites. The thermal residual stresses in each constituent phase were measured by the neutron diffraction. The measured residual stress was compared with the theoretical value calculated by Eshelby's inclusion model $[7,8]$.

\section{EXPERIMENTAL PROCEDURE}

\subsection{Materials and Specimens}

The experimental materials used were ceramic composites of alumina mixed with various volume fractions of zirconia, $\mathrm{Al}_{2} \mathrm{O}_{3} / \mathrm{ZrO}_{2}$, and of silicon carbide, $\mathrm{Al}_{2} \mathrm{O}_{3} /$ $\mathrm{SiC}$. The crystal structure of the alumina is the trigonal $\left(\alpha-\mathrm{Al}_{2} \mathrm{O}_{3}\right)$. The zirconia and the silicon carbide have the tetragonal structure containing $3 \mathrm{~mol} \%$ yttria and the cubic structure $(\beta-\mathrm{SiC})$, respectively. For the case of $\mathrm{Al}_{2} \mathrm{O}_{3} / \mathrm{ZrO}$ composites, the volume fraction of zirconia is $0,14.1,30.4,49.6,72.4$ and $100 \%$ as summarized in Table 1 . The materials were hipped at $1450^{\circ} \mathrm{C}$ for $1 \mathrm{~h}$ under $98 \mathrm{MPa}$ in Ar gas. The microstructure of $\mathrm{Al}_{2} \mathrm{O}_{3} / \mathrm{ZrO}_{2}$ composites is a uniform mixture of equi-axial grains of $\mathrm{ZrO}_{2}$ and $\mathrm{Al}_{2} \mathrm{O}_{3}$ with sizes less than a micrometer [9]. The coefficient of thermal expansion (CTE) of monolithic ceramics of zirconia and alumina is $10.9 \times 10^{-6}$ and $8.5 \times 10^{-6} /{ }^{\circ} \mathrm{C}$, respectively. The CTE value of zirconia is larger than that of alumina. For the composite of $\mathrm{Al}_{2} \mathrm{O}_{3}$ / $\mathrm{SiC}$, the volume fraction of silicon carbide is $0,3,7,14$ and $26 \%$. The composites were hipped under $40 \mathrm{MPa}$. The hipping temperature was determined between $1300^{\circ} \mathrm{C}$ and $1900^{\circ} \mathrm{C}$ to achieve the maximum flexural

Table 1. Experimental materials.

\begin{tabular}{l|c|c}
\hline Material & $\mathrm{ZrO}_{2}$ content(vol\%) & SiC content (vol\%) \\
\hline $\mathrm{Al}_{2} \mathrm{O}_{3} / 3 \mathrm{~mol} \% \mathrm{Y}_{2} \mathrm{O}_{3}-\mathrm{ZrO}_{2}$ & $0,14.1,30.4,49.6,72.4,100$ & - \\
\hline $\mathrm{Al}_{2} \mathrm{O}_{3} / \mathrm{SiC}$ & - & $0,7,14,26,100$ \\
\hline
\end{tabular}

Received April 4, 2000

Accepted October 11, 2000

Original paper in Japanese was published in Journal of the Society of Materials Science, Japan, Vol. 49, No. 7 (2000) pp. $742-747$. 
Table 2. Properties of monolithic materials.

\begin{tabular}{c|c|c|c}
\hline Material & $\begin{array}{c}\text { Young's } \\
\text { modulus } \\
\mathrm{E}_{\mathrm{M}}(\mathrm{GPa})\end{array}$ & $\begin{array}{c}\text { Poisson's } \\
\text { ratio } \\
v_{\mathrm{M}}\end{array}$ & $\begin{array}{c}\text { Coefficient } \\
\text { of thermal } \\
\text { expantion } \\
a\end{array}$ \\
\hline $\mathrm{Al}_{2} \mathrm{O}_{3}$ & 406 & 0.231 & $8.5 \times 10^{-6}$ \\
\hline $3 \mathrm{~mol} \% \mathrm{Y}_{2} \mathrm{O}_{3}-\mathrm{ZrO}_{2}$ & 214 & 0.310 & $10.9 \times 10^{-6}$ \\
\hline $\mathrm{SiC}$ & 402 & 0.182 & $4.7 \times 10^{-6}$ \\
\hline
\end{tabular}

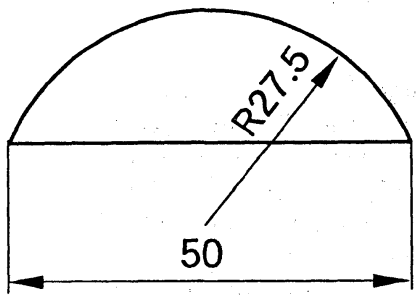

$t=4$

(a) $\mathrm{Al}_{2} \mathrm{O}_{3} / \mathrm{ZrO}_{2}$

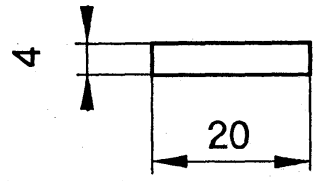

$t=3$

(b) $\mathrm{Al}_{2} \mathrm{O}_{3} / \mathrm{SiC}$
Fig. 1. Shape and dimensions of specimen.

strength. In $\mathrm{Al}_{2} \mathrm{O}_{3} / \mathrm{SiC}$ composites, nano-scale particles of silicon carbide are distributed along the grain boundary or within the grain of alumina whose size is about half to one micrometer [2]. The CTE value of monolithic silicon carbide is $4.7 \times 10^{-6} /{ }^{\circ} \mathrm{C}$. The CTE value of silicon carbide is smaller than that of alumina. The mechanical elastic constants and the CTE of monolithic ceramics are summarized in Table 2. The elastic constants of the zirconia were experimental values $[10,11]$. For the cases of alumina and silicon carbide, the values were calculated by using Kröner's model from the elastic constants of single crystals [12-14].

Figure 1 shows the shape and dimensions of the specimens. For the case of $\mathrm{Al}_{2} \mathrm{O}_{3} / \mathrm{ZrO}_{2}$ composites, the bowshaped specimen was cut off from a disk with a radius of $27.5 \mathrm{~mm}$ and a thickness of $4 \mathrm{~mm}$. For the case of $\mathrm{Al}_{2} \mathrm{O}_{3} /$ $\mathrm{SiC}$ composites, the rectangular specimen with a height of $4 \mathrm{~mm}$, a width of $3 \mathrm{~mm}$ and a length of $20 \mathrm{~mm}$ was used.

\subsection{Neutron Diffraction Measurement}

The neutron stress measurement was performed for $\mathrm{Al}_{2} \mathrm{O}_{3} 113, \mathrm{Al}_{2} \mathrm{O}_{3} 116, \mathrm{ZrO}_{2} 202, \mathrm{SiC} 220$ and $\mathrm{SiC} 311$ diffractions with the RESA (REsidual Stress Analyze equipment) at JAERI (Japan Atomic Energy Research Institute). The specimen was placed on the turntable, and rotated at 10 to $13 \mathrm{rpm}$. For the case of $\mathrm{Al}_{2} \mathrm{O}_{3} / \mathrm{SiC}$ composites, three specimens were placed on the table. The parallel beam slits were attached to receiving side of a goniometer. The slits with a height of $15 \mathrm{~mm}$ and a width of $10 \mathrm{~mm}$ were also attached to divergent and receiving sides. The irradiated volume is about $800 \mathrm{~mm}^{3}$ for $\mathrm{Al}_{2} \mathrm{O}_{3}$ $1 \mathrm{ZrO}_{2}$ composites and $540 \mathrm{~mm}^{3}$ for $\mathrm{Al}_{2} \mathrm{O}_{3} / \mathrm{SiC}$ composites. The wave length used was $0.20995,0.20946$ and $0.20888 \mathrm{~nm}$. The scanning speed was $0.1 \mathrm{deg} / \mathrm{step}$. The preset time was determined between 30 to $600 \mathrm{~s}$ on the basis of the diffraction intensity. The conditions of neutron stress measurement were summarized in Table 3.

\subsection{Thermal Residual Stress in Composite}

The residual stress induced by the CTE mismatch has been analyzed by Taya et al. [8] on the basis of Eshelby's inclusion model [7]. The thermal residual stresses in the matrix, $\left\langle\sigma_{\mathrm{m}}\right\rangle$, and in the inclusion, $\left\langle\sigma_{\mathrm{p}}\right\rangle$, are given by

$$
\begin{aligned}
& \frac{\left\langle\sigma_{p}\right\rangle}{E_{m}}=-\frac{2\left(1-V_{f}\right) \beta \alpha^{*}}{A}, \\
& \frac{\left\langle\sigma_{m}\right\rangle}{E_{m}}=\frac{2 V_{f} \beta \alpha^{*}}{A},
\end{aligned}
$$

where

$$
\begin{aligned}
& A=\left(1-V_{f}\right)(\beta+2)\left(1+v_{m}\right)+3 \beta V_{f}\left(1-v_{m}\right), \\
& \beta=\left(1+v_{m}\right) E_{p} /\left(1-2 v_{p}\right) E_{m}, \\
& \alpha^{*}=\left(\alpha_{p}-\alpha_{m}\right) \Delta T .
\end{aligned}
$$

\begin{tabular}{|c|c|c|c|c|c|c|}
\hline \multirow{2}{*}{$\begin{array}{l}\text { Equipment } \\
\text { Diffraction line }\end{array}$} & \multicolumn{6}{|c|}{ RESA(REsidual Stress Analyzer equipment) } \\
\hline & $\mathrm{Al}_{2} \mathrm{O}_{3} 116$ & $\mathrm{ZrO}_{2} 202$ & $\operatorname{SiC} 220$ & $\mathrm{SiC} 311$ & $\mathrm{Al}_{2} \mathrm{O}_{3} 113$ & $\mathrm{Al}_{2} \mathrm{O}_{3} 116$ \\
\hline Diffraction angle & 81.94 & 70.5 & $85.62,85.33$ & $105.66,105.25$ & $60.30,60.12$ & $81.71,81.43$ \\
\hline Wave length & \multicolumn{2}{|c|}{0.20995} & \multicolumn{4}{|c|}{$0.20946, \quad 0.20888$} \\
\hline Monocrometer & \multicolumn{6}{|c|}{ Si 311} \\
\hline Detecter & \multicolumn{6}{|c|}{$3 \mathrm{He}-0 \mathrm{D}$} \\
\hline Scanning speed (deg/step) & \multicolumn{6}{|c|}{0.1} \\
\hline Preset time & $40 \sim 90$ & $40 \sim 120$ & $240 \sim 600$ & $240 \sim 600$ & $30 \sim 120$ & $30 \sim 120$ \\
\hline
\end{tabular}

$E_{\mathrm{m}}, v_{\mathrm{m}}$ and $\alpha_{\mathrm{m}}$ are Young's modulus, Poisson's ratio and CTE of the matrix, and $E_{\mathrm{p}}, v_{\mathrm{p}}$ and $\alpha_{\mathrm{p}}$ are those of the

Table 3. Neutron diffraction conditions. 
inclusion. $V_{\mathrm{f}}$ and $\Delta T$ are the volume fraction of inclusion and the change of temperature, respectively.

The thermal residual stress can be regarded as equitriaxial. Once the residual strain, $\varepsilon$, is obtained, the residual stress can be calculated by

$$
\sigma_{R}=3 K \varepsilon,
$$

where $K$ is the bulk modulus. The diffraction value of bulk modulus of alumina and silicon carbide was calculated by Kröner's model from the elastic constants of single crystals under the assumption of random orientation. For the case of zirconia, it was calculated from the mechanical elastic constants. The calculated values are summarized in Table 4.

\section{EXPERIMENTAL RESULTS AND DISCUSSION}

\subsection{Diffraction Profile}

Typical examples of the $\mathrm{ZrO}_{2} 202$ diffraction obtained for $\mathrm{Al}_{2} \mathrm{O}_{3} / \mathrm{ZrO}_{2}$ composites with the zirconia volume fraction of 14,72 and $100 \%$ are shown in Fig. 2(a). The preset time for the composites with $V_{\mathrm{f}}=14,72$ and $100 \%$ was 120,90 and $40 \mathrm{~s}$, respectively. The profile is the doublet with $\mathrm{ZrO}_{2} 202$ and $\mathrm{ZrO}_{2} 220$ diffractions. Each diffraction was separated by assuming two Gaussian curves. The curves in the figure indicate the fitted results. The diffraction angle increases with the zirconia volume fraction. Figure 2(b) shows the profiles of the $\mathrm{Al}_{2} \mathrm{O}_{3} 116$ diffraction obtained for $\mathrm{Al}_{2} \mathrm{O}_{3} / \mathrm{ZrO}_{2}$ composites with $V$ $=0,14$ and $72 \%$. The preset time for the composites with $V_{\mathrm{f}}=0,14$ and $72 \%$ was 40,60 and $90 \mathrm{~s}$, respectively. The data was approximated by the Gaussian curve. The diffraction angle also increases with the zirconia volume fraction.

For the case of $\mathrm{Al}_{2} \mathrm{O}_{3} / \mathrm{SiC}$ composites, the profile of $\mathrm{SiC} 220$ diffraction was overlapped with the $\mathrm{Al}_{2} \mathrm{O}_{3} 211$ diffraction as shown in Fig. 3(a). The profile was obtained for the composite with the silicon carbide volume fraction of $26 \%$. The preset time was $600 \mathrm{~s}$. The diffraction angle was also determined by using the wave separation technique. Figure $3(\mathrm{~b})$ shows the example of the

Table 4. Bulk modulus of monolithic materials.

\begin{tabular}{c|c}
\hline $\begin{array}{c}\text { Diffraction } \\
\text { plane }\end{array}$ & $\begin{array}{c}\text { Bulk modulus } \\
\mathrm{K} \\
(\mathrm{GPa})\end{array}$ \\
\hline $\mathrm{SiC} 220$ & 211.0 \\
\hline $\mathrm{SiC} 311$ & 211.0 \\
\hline $\mathrm{Al}_{2} \mathrm{O}_{3} 113$ & 246.2 \\
\hline $\mathrm{Al}_{2} \mathrm{O}_{3} 116$ & 248.5 \\
\hline $\mathrm{ZrO}_{2} 202$ & 187.7 \\
\hline
\end{tabular}

$\mathrm{Al}_{2} \mathrm{O}_{3} 113$ diffraction. The preset time was $120 \mathrm{~s}$. For the cases of $\mathrm{Al}_{2} \mathrm{O}_{3} 113, \mathrm{Al}_{2} \mathrm{O}_{3} 116$ and $\mathrm{SiC} 311$ diffractions, the profile had a single peak.

\subsection{Thermal Residual Stress}

Figure 4 shows the change of the residual strain with the zirconia volume fraction obtained for $\mathrm{Al}_{2} \mathrm{O}_{3} / \mathrm{ZrO}_{2}$ composites. The reference angle used to calculate the residual strain was the value obtained from hipped monolithic alumina and zirconia. For the case of the zirconia phase, the tensile residual strain was measured, because the CTE value of zirconia is larger than that of alumina. The tensile strain decreases with increasing zirconia volume fraction. On the other hand, the compressive residual strain was observed in the alumina phase. The compressive residual strain increases with the zirconia volume fraction.

Figure 5 shows the change of the residual strain with the volume fraction of the silicon carbide obtained for

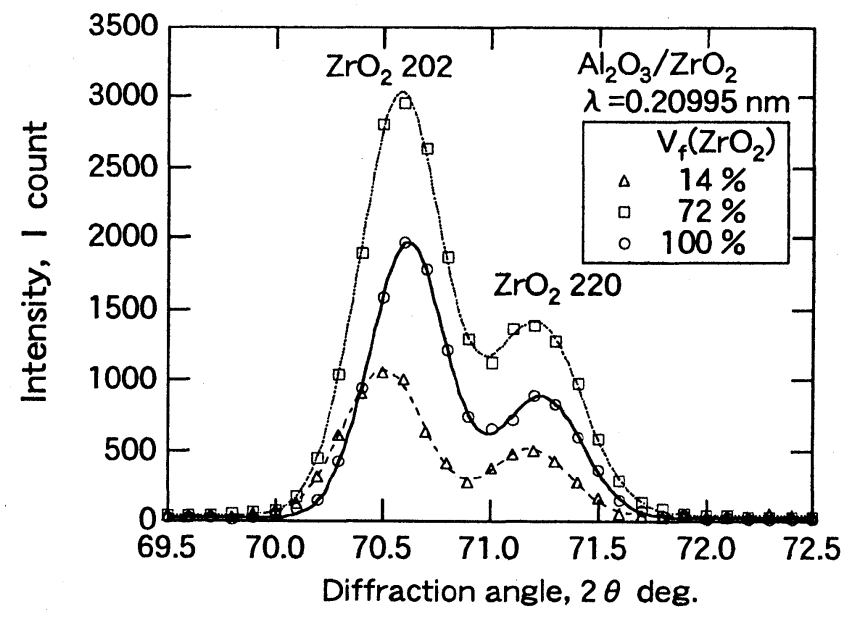

(a) $\mathrm{ZrO}_{2} 202$ diffraction

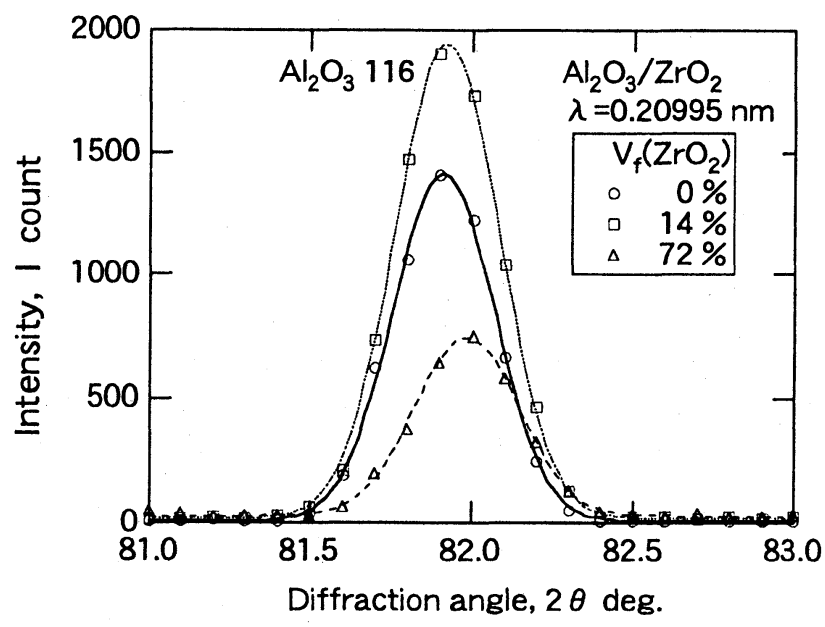

(b) $\mathrm{Al}_{2} \mathrm{O}_{3} 116$ diffraction

Fig. 2. Neutron diffraction profiles for $\mathrm{Al}_{2} \mathrm{O}_{3} / \mathrm{ZrO}_{2}$. 


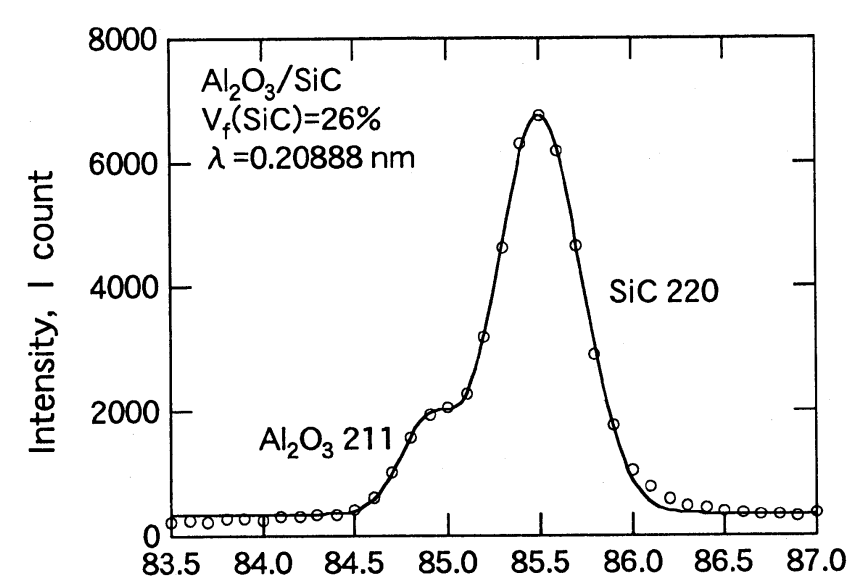

Diffraction angle, $2 \theta$ deg.

(a) $\mathrm{SiC} 220$ diffraction

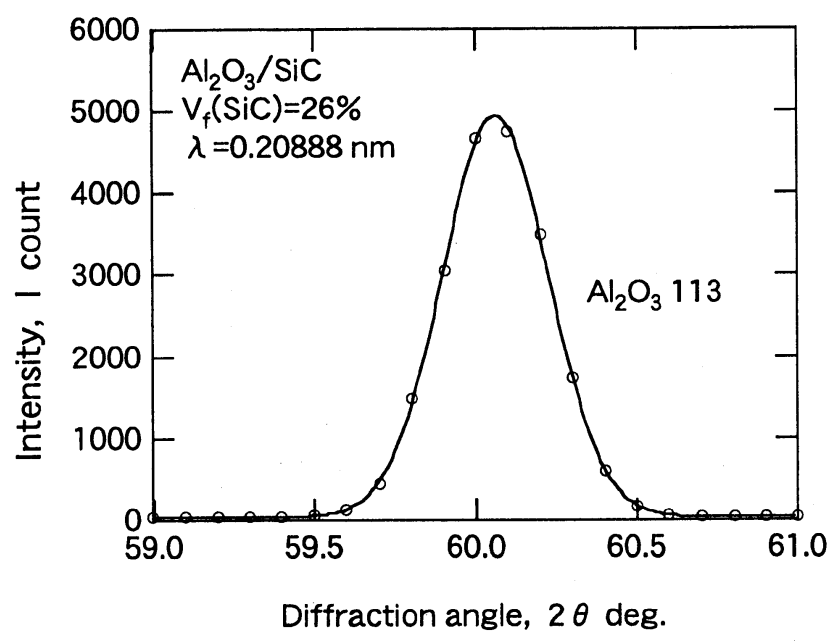

(b) $\mathrm{Al}_{2} \mathrm{O}_{3} 113$ diffraction

Fig. 3. Neutron diffraction profiles for $\mathrm{Al}_{2} \mathrm{O}_{3} / \mathrm{SiC}$.

$\mathrm{Al}_{2} \mathrm{O}_{3} / \mathrm{SiC}$ composites. The diffraction angle measured from the silicon carbide powder was used as a reference. The residual strain in the silicon carbide phase is compression, because the CTE value of alumina is larger than that of silicon carbide. The compressive residual strain increases with the silicon carbide volume fraction. The absolute value of the compressive strain obtained for $\mathrm{SiC}$ 311 diffraction is larger than that for $\mathrm{SiC} 220$ diffraction. On the other hand, the residual strain in the alumina phase is tension. The tensile residual strain increases with silicon carbide volume fraction.

Since the specimen was rotated on the turntable, the measured strain is the average value of the strain in the direction perpendicular to the axis of rotation. The residual strain in the direction parallel to the axis of rotation

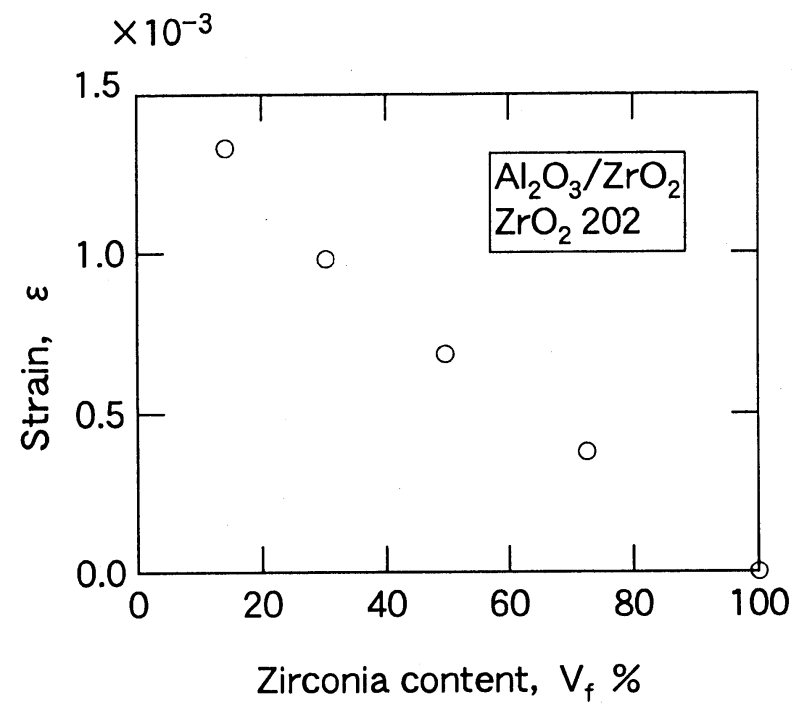

(a) $\mathrm{ZrO}_{2}$ phase

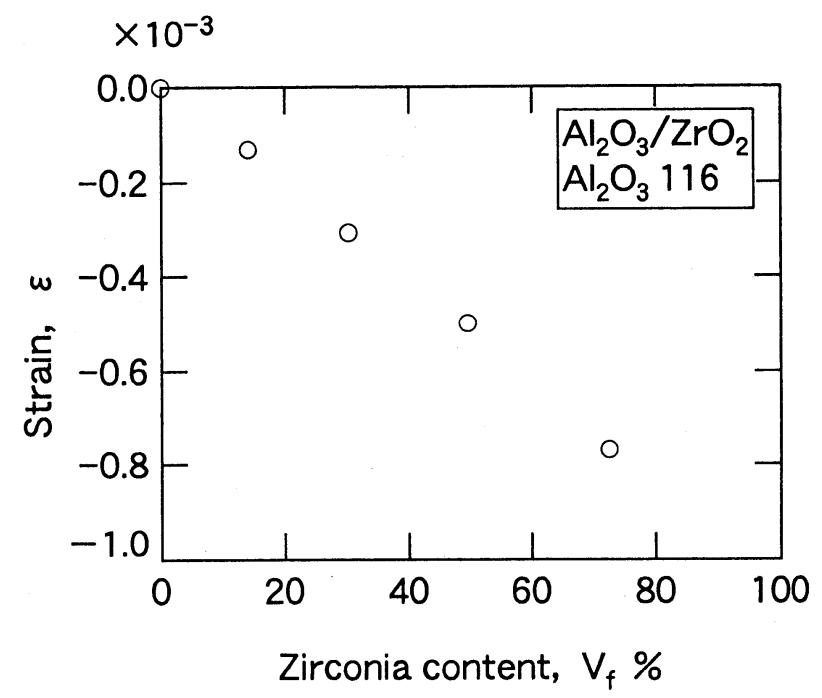

(b) $\mathrm{Al}_{2} \mathrm{O}_{3}$ phase

Fig. 4. Residual strain in $\mathrm{Al}_{2} \mathrm{O}_{3} / \mathrm{ZrO}_{2}$ composites.

was assumed to be the same as the measured value. The residual stress was calculated by using Eq. (6). Figure 6 shows the variation of the residual stress with the zirconia volume fraction obtained for $\mathrm{Al}_{2} \mathrm{O}_{3} / \mathrm{ZrO}_{2}$ composites. In the figure, the curves indicate the predicted value calculated from Eqs. (1) and (2) by regarding alumina or zirconia as the matrix phase. The composites were assumed to be subjected to a temperature change of $\Delta T=1425^{\circ} \mathrm{C}$. For the case of the zirconia volume fraction of $14 \%$, the residual stress in the zirconia phase is $750 \mathrm{MPa}$. When the volume fraction is larger than $50 \%$, the experimental results agree well with the prediction which is calculated as the zirconia matrix.

For the case of $\mathrm{Al}_{2} \mathrm{O}_{3} / \mathrm{SiC}$ composites, the change of the residual stress with the silicon carbide volume frac- 


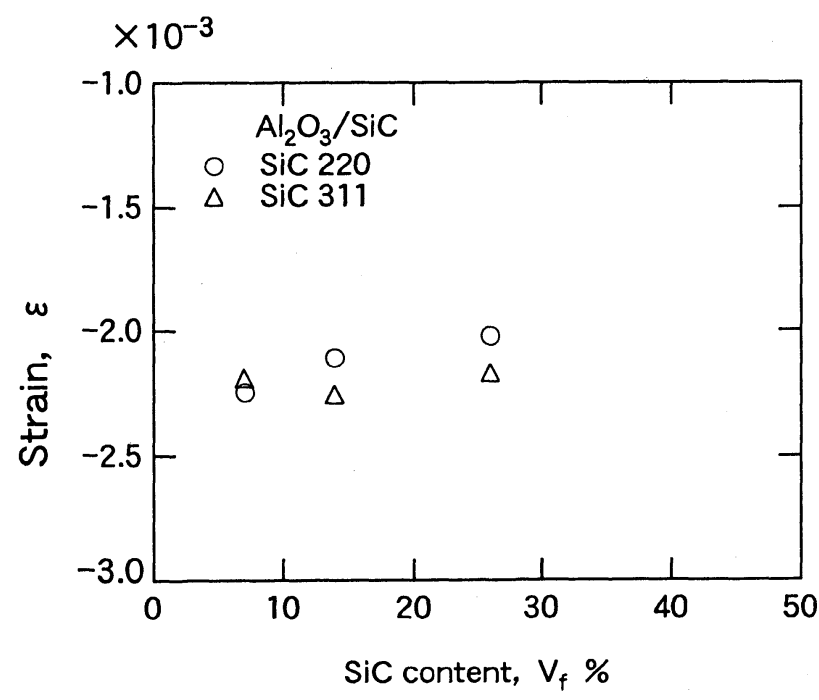

(a) $\mathrm{SiC}$ phase

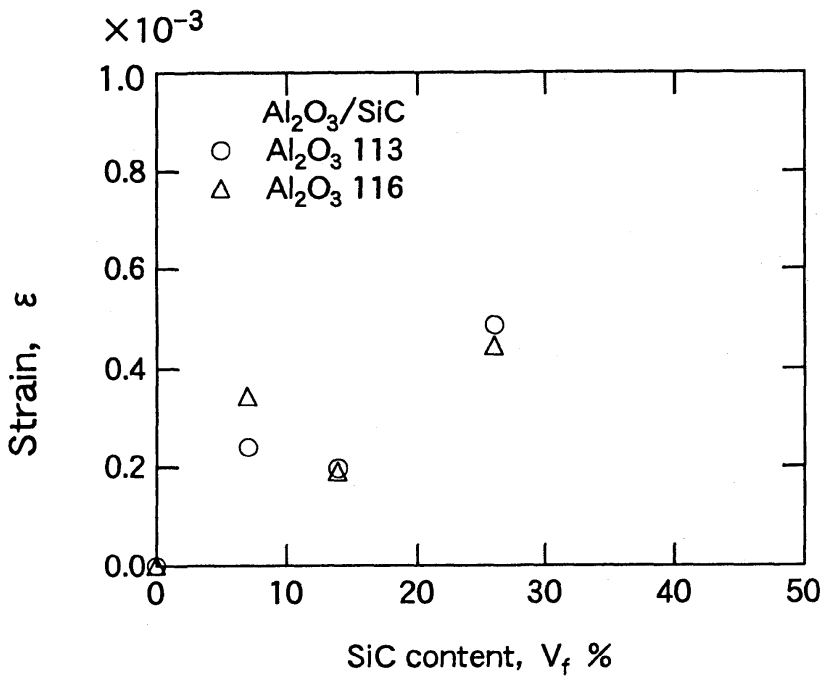

(b) $\mathrm{Al}_{2} \mathrm{O}_{3}$ phase

Fig. 5. Residual strain in $\mathrm{Al}_{2} \mathrm{O}_{3} / \mathrm{SiC}$ composites.

tion is shown in Fig. 7. The residual stresses of both phases obtained from two diffractions are close. The temperature change of $\Delta T=1200^{\circ} \mathrm{C}$ was assumed for prediction [2]. The residual stresses in both phases agree very well with the predicted values.

When the coefficient of thermal expansion of the matrix is larger than that of inclusion, the residual stress of the matrix becomes tension. The tensile residual stress increases with the volume fraction of the inclusion. On the other hand, the compressive residual stress was introduced in the inclusion. The residual stress has a significant influence on the strength and toughness of composites [8]. The control of the residual stress plays a key role in designing ceramic composites. The neutron dif-

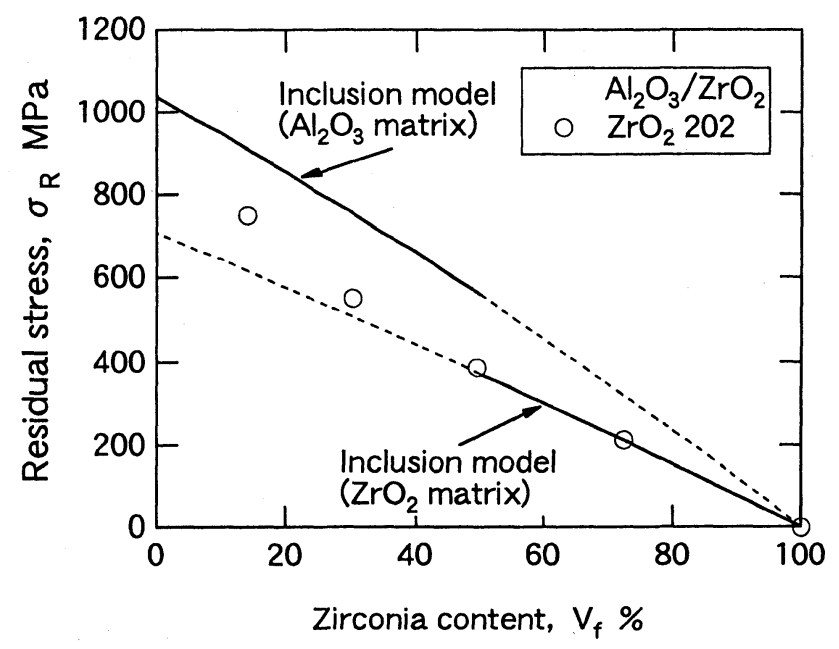

(a) $\mathrm{ZrO}_{2}$ phase

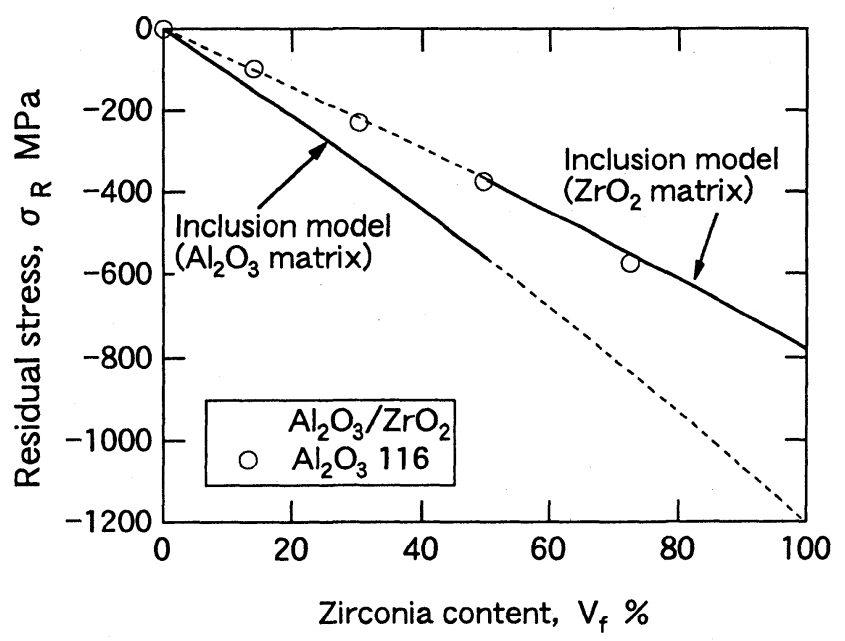

(b) $\mathrm{Al}_{2} \mathrm{O}_{3}$ phase

Fig. 6. Residual stress in $\mathrm{Al}_{2} \mathrm{O}_{3} / \mathrm{ZrO}_{2}$ composites.

fraction method is one of the most effective methods to measure them.

\section{CONCLUSIONS}

The thermal residual stress in ceramic composites of alumina mixed with various volume fractions of zirconia, and of silicon carbide was measured by the neutron diffraction method. The measured residual stress was compared with the predicted values calculated by Eshelby's inclusion model.

(1) When the coefficient of thermal expansion of the matrix is larger than that of inclusion, the residual stress of the matrix becomes tension. The tensile residual stress 
Yoshiaki AkInIwa, Keisuke TANAKA, Nobuaki MinaKaWA and Yukio MoRII

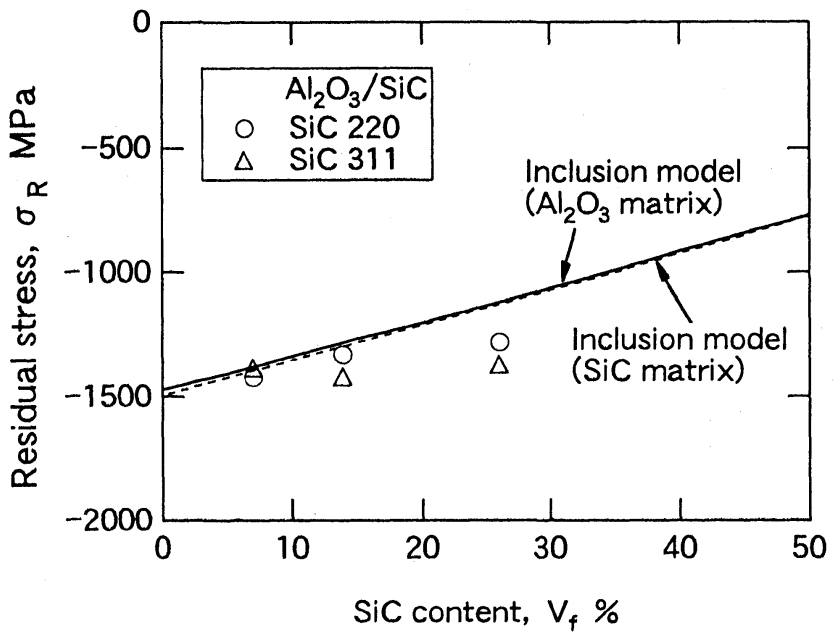

(a) $\mathrm{SiC}$ phase

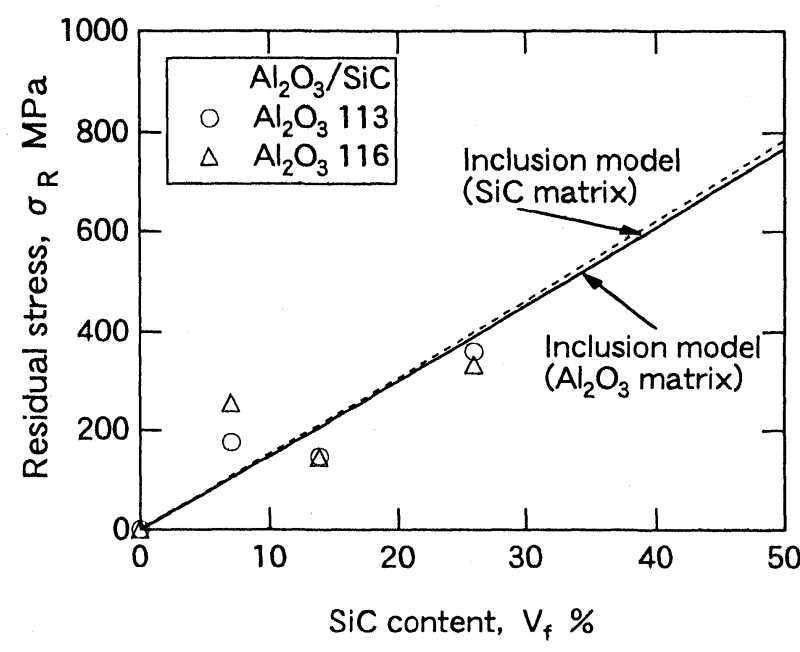

(b) $\mathrm{Al}_{2} \mathrm{O}_{3}$ phase

Fig. 7. Residual stress in $\mathrm{Al}_{2} \mathrm{O}_{3} / \mathrm{SiC}$ composites.

increases with the volume fraction of the inclusion.

(2) For the case of the composites of alumina mixed with various volume fractions of silicon carbide, the residual stresses obtained from two different diffractions are very close.

(3) The residual stress measured by the neutron method agreed well with the theoretical prediction based on Eshelby's inclusion model.

\section{REFERENCES}

1. K. Tanaka, M. Matsui, R. Shikata and T. Nishikawa, J. Soc. Mater. Sci., Japan, 41 (1992) 593 (in Japanese).

2. J. Otsuka, S. Iio, Y. Tajima, M. Watanabe and K. Tanaka, J. Ceram. Soc., Japan, 102 (1994) 29 (in Japanese).

3. K. Tanaka, Y. Yamamoto, N. Mine, K. Suzuki and H. Nakagawa, Trans. Japan Soc. Mech. Eng., A, 56 (1990) 402 (in Japanese).

4. K. Tanaka, N. Mine, K. Suzuki, J. Soc. Mater. Sci., Japan, 39 (1990) 1235 (in Japanese).
5. Y. Akiniwa, K. Tanaka, T. Takezono, N. Minakawa and Y. Morii, Proc. 5th Int. Conf. Residual Stress, 2 (1997) 982.

6. Y. Akiniwa, K. Tanaka, T. Takezono, N. Minakawa and Y. Morii, J. Soc. Mater. Sci., Japan, 47 (1998) 755 (in Japanese).

7. J. D. Eshelby, Proc. Roy. Soc., A241 (1957) 376.

8. M. Taya, S. Hayashi, A. S. Kobayashi and H. S. Yoon, J. Am. Ceram. Soc., 73 (1990) 1382.

9. R. Shikata, Y. Urata, T. Shiono and Y. Nishikawa, J. Japan Soc. Powder and Powder Metallurgy, 37 (1990) 357 (in Japanese).

10. K. Tanaka, Y. Yamamoto and K. Suzuki, Proc. 2nd Int. Conf. Residual Stress (1989) 382.

11. K. Tanaka, T. Kurimura, Y. Akiniwa, K. Suzuki and H. Nakagawa, Trans. Japan Soc. Mech. Eng., A, 55 (1989) 318 (in Japanese).

12. E. Kröner, Z. Phys., 151 (1958) 504.

13. W. E. Trefft, J. Res. Nat. Bur. Standard, 70A (1966) 277.

14. K. B. Tolpygo, Soviet Phys. Solid State, 2 (1961) 2367. 